\title{
Seleção de famílias para aparência dos tubérculos e tolerância a temperaturas elevadas em batata
}

\author{
Guilherme Henrique Martins Rodrigues Ribeiro $\left({ }^{1 *}\right)$; César Augusto Brasil Pereira Pinto (1); \\ Izabel Cristina Rodrigues Figueiredo ('); Carolina Mariane Moreira (1); Danilo Hottis Lyra ( $\left.{ }^{2}\right)$ \\ (') Universidade Federal de Lavras (UFLA), Departamento de Biologia, Caixa Postal 3037, 37200-000 Lavras (MG), Brasil. \\ (2) Universidade de São Paulo (USP), Escola Superior de Agricultura “Luiz de Queiroz” (ESALQ), Departamento de Genética, \\ Av. Pádua Dias, 11, 13418-900 Piracicaba (SP), Brasil. \\ ${ }^{*}$ ) Autor correspondente: ghmribeiro2@yahoo.com.br
}

Recebido: 3/abr./2014; Aceito: 14/set./2014

\begin{abstract}
Resumo
A seleção de famílias é um método que possibilita maior eficiência nos programas de melhoramento, já que as famílias inferiores são descartadas e concentram-se os recursos nas famílias mais promissoras. O objetivo deste estudo foi avaliar a eficiência da seleção de famílias para os caracteres de aparência e de produção de tubérculos em condições de calor e temperatura amenas. Utilizaram-se neste estudo famílias geradas do cruzamento biparental entre clones tolerantes ao calor e cultivares de boa aparência dos tubérculos. Foram avaliados caracteres de aparência, produtividade e peso específico de tubérculos na geração seedling, primeira e segunda geração clonal. Para os caracteres de aparência dos tubérculos, algumas famílias se destacaram na geração seedling por apresentarem maior frequência de clones superiores. Na primeira e segunda geração clonal identificaram-se famílias tolerantes ao calor e responsivas para melhorias, nas condições de temperatura amena, em produtividade e peso específico dos tubérculos. Concluiu-se que a seleção de famílias para produtividade e peso específico dos tubérculos foi eficiente e que a seleção de famílias para o conjunto de caracteres de aparência dos tubérculos se mostrou menos eficiente.
\end{abstract}

Palavras-chave: Solanum tuberosum L., estresse abiótico, famílias clonais.

\section{Selection of families for tubers appearance and tolerance to elevated temperatures in potato}

\begin{abstract}
Family selection is a method which allows a greater efficiency in breeding programs, since the lower performance families are discarded and focuses are thrown on those most promising families. The aim of this study was to evaluate the efficiency of family selection for traits of tuber appearance and tuber yield under warm and mild temperatures. In this study families were generated by biparental crosses between heat tolerant clones and commercial cultivars with and good tuber appearance. Traits of tuber appearance, tuber yield and tuber specific gravity were evaluated in the seedling, first and second clonal generations. Regarding the traits of tuber appearance some families presented higher frequency of superior clones in the seedling generation. In the first and second generations heat tolerant families were identified which showed positive responsiveness to mild temperatures for tuber yield and tuber specific gravity. It was concluded that family selection for tuber yield and tuber specific gravity was efficient, but family selection for all traits related to tuber appearance was less effective.
\end{abstract}

Key words: Solanum tuberosum L., abiotic stress, clonal families.

\section{INTRODUÇÃO}

Os programas de melhoramento de batata geralmente começam com cruzamentos biparentais, em que são obtidas populaçóes com grande número de clones nas geraçóes iniciais. Os clones obtidos são avaliados visualmente para caracteres de aparência dos tubérculos e a batata-semente é multiplicada para a condução de ensaios em maior escala nas geraçóes subsequentes. Esse procedimento é conhecido como seleção clonal, que consiste simplesmente na identificação dos melhores indivíduos da população. A seleção clonal tem-se mostrado pouco eficiente devido à quantidade limitada de material propagativo nas geraçóes iniciais e aos experimentos serem conduzidos sem repetiçáo, resultando em baixa precisão na avaliação (Diniz et al., 2006). Alternativa para a seleção clonal é a seleção de famílias, que consiste em identificar as famílias superiores, onde provavelmente estão os clones mais promissores. 
Famílias com baixo desempenho são completamente eliminadas e nenhum de seus clones é avaliado nas geraçôes mais avançadas (Diniz et al., 2006).

Sabe-se que em batata, assim como na maioria das culturas, a variância genética dentro de famílias é maior que a variância entre famílias, para os caracteres agronômicos (Bradshaw et al., 1998; Diniz et al., 2006; Gopal, 2001; Melo et al., 2011), indicando que é dentro das melhores famílias que se alcança grande potencial de seleçáo. Segundo Diniz et al. (2006), as melhores famílias contêm maior número de clones superiores e os poucos clones com bom desempenho dentro das famílias inferiores, na sua grande maioria, não superam os melhores clones das outras famílias. E a seleção das melhores famílias nas geraçôes iniciais implica em reduçáo no número de clones a serem avaliados nas geraçóes mais avançadas, levando à economia de recursos, além de permitir maior precisão nas avaliações dos clones retidos.

A seleção de famílias em batata visa reduzir o tamanho da população inicial, uma vez que o foco do melhoramento é a obtenção de novos clones (Benavente e Pinto, 2012). A seleção de famílias baseada na avaliação em diferentes ambientes é uma boa estratégia para a obtenção de clones com adaptação ampla, devendo a seleção ser realizada com base na média dos ambientes (Lambert et al., 2006; Simon et al., 2009). Simon et al. (2009), trabalhando com 22 famílias clonais em três ambientes, observaram uma grande interação entre famílias e ambientes para o peso específico dos tubérculos. Esses autores verificaram que maiores progressos genéticos são obtidos com a seleção de famílias para determinado ambiente, porém que é possível realizar a seleção de famílias com adaptação ampla.

Alguns fatores interferem no desenvolvimento da cultura da batata em regiôes tropicais como, por exemplo, temperatura, fotoperíodo, maior pressão de pragas e doenças, entre outros. As temperaturas elevadas são o principal fator de perdas na qualidade, causando grandes prejuízos na produção, na matéria seca dos tubérculos e também depreciando a aparência deles. Segundo Levy e Veilleux (2007), os principais efeitos de temperaturas elevadas na cultura da batata são crescimento acelerado, fotossíntese reduzida e respiração aumentada, início da tuberização e crescimento de tubérculos inibidos, maior número de tubérculos com desordens fisiológicas, dormência dos tubérculos reduzida ou suprimida, teor de matéria seca reduzido e também nível de glicoalcaloides elevado.

Para os caracteres produção e resistência a doenças, a seleção de família tem se mostrado eficiente (Amaro et al., 2003; Bradshaw et al., 1998; Diniz et al., 2006; Gopal, 2001; Melo et al., 2011). Contudo, poucos trabalhos têm sido realizados na avaliação da eficiência da seleção de famílias para os caracteres de aparência dos tubérculos. Este trabalho teve como objetivo avaliar a viabilidade da seleção de famílias para produtividade, peso específico e aparência dos tubérculos em condiçóes contrastantes de temperatura.

\section{MATERIAL E MÉTODOS}

As famílias foram obtidas pelo cruzamento de seis cultivares comerciais (Caesar, Cupido, Markies, Monalisa, Vivaldi e Voyager) e oito clones do programa de melhoramento genético da batata da UFLA (CBM 04-48, CBM 07-78, CBM 16-16, CBM 22-19, SR1 07-16, SR2 21-02, SR2 35-05 e SR2 50-02) no esquema dialélico parcial (cultivares $\times$ clones), sendo produzidas 22 famílias clonais. As cultivares escolhidas apresentavam ótima aparência de tubérculos, isto é, pele amarelo-clara, lisa e brilhante, olhos rasos, formato alongado ou oval, polpa de cor creme, livre de desordens internas ou externas, e os clones foram escolhidos por apresentarem tolerância ao calor, alto potencial produtivo e alto teor de matéria seca nos tubérculos.

As sementes botânicas foram semeadas em bandejas de isopor e as plântulas foram posteriormente transplantadas para vasos plásticos de $10 \mathrm{~cm}$ de diâmetro para produzir a geração seedling (GS). De cada família foram cultivadas aproximadamente 100 plântulas na GS (uma plântula por vaso). A colheita foi realizada aproximadamente aos 100 dias após o plantio e coletou-se um tubérculo de cada clone, os quais foram avaliados individualmente. Três avaliadores atribuíram notas para os caracteres aparência de tubérculos, formato de tubérculos, profundidade de olhos (gemas) e aspereza da pele, empregando-se uma escala de notas que variava de 1 (pior desempenho) a 5 (melhor desempenho). $\mathrm{Na}$ GS, a nota de cada família para os caracteres de aparência foi calculada pela média dos clones pertencentes à família. A produtividade e o peso específico de tubérculos foram obtidos de amostras contendo um tubérculo de cada clone da família, dividido pelo número de clones.

Os experimentos da primeira geração clonal (PGC) e segunda geração clonal (SGC) foram conduzidos em campo, ambos no município de Pouso Alegre, MG, situado a uma altitude de 832 metros, em um Latossolo Vermelho-amarelo de textura argilosa. Na PCG, os ensaios foram instalados no delineamento de blocos casualizados com três repetiçóes, sendo as parcelas representadas por 10 clones de cada família, espaçados de $0,80 \times 0,50 \mathrm{~m}$. Como testemunhas foram usadas as cultivares Caesar e Voyager e os clones tolerantes ao calor, segundo Lambert et al. (2006), CBM 16-16 e CBM 22-19. Os ensaios foram conduzidos no período de novembro de 2011 a março de 2012 (safra das águas - temperaturas elevadas).

Para condução dos experimentos da SGC utilizaram-se 20 clones de 22 famílias, totalizando 440 clones. Vale ressaltar que os clones utilizados nesse experimento não foram necessariamente os mesmos utilizados na geração anterior, mas sim uma amostra aleatória obtida dentro de cada família. O experimento da SGC foi montado no delineamento de blocos casualizados com 20 repetiçôes por família e as parcelas foram constituídas por cinco plantas de um clone de cada família. As testemunhas foram as mesmas 
da geração anterior. $\mathrm{O}$ ensaio foi conduzido também no município de Pouso Alegre, MG, no período entre junho a outubro de 2012 (safra de inverno - temperaturas amenas). O espaçamento utilizado foi de $0,3 \mathrm{~m}$ entre plantas $0,8 \mathrm{~m}$ entrelinhas.

Nos experimentos da PGC e da SGC, a adubação utilizada foi de $3.500 \mathrm{~kg} \mathrm{ha}^{-1}$ de fertilizante formulado 04-14-08 ( $\left.\mathrm{N}_{2} \mathrm{P}_{2} \mathrm{O}_{5}, \mathrm{~K}_{2} \mathrm{O}\right)$ no plantio e no momento da amontoa foi realizada adubaçáo de cobertura com $400 \mathrm{~kg}$ $\mathrm{ha}^{-1} \mathrm{de}$ fertilizante formulado 20-05-20. O preparo de solo foi realizado de maneira usual para a cultura, com aração seguida de gradagem e enxada rotativa, e o manejo de irrigação por aspersão foi feito com turno de rega fixo de sete dias. As pulverizações com defensivos para controle de pragas e doenças foram realizadas conforme a prática dos produtores na região e a dessecação das ramas ocorreu aos 110 dias após o plantio.

Foram avaliados os seguintes caracteres dos tubérculos na PGC e na SGC: formato (nota 1 = redondo a nota 5 = alongado), profundidade de olhos (nota $1=$ olhos profundos a nota $5=$ olhos rasos), defeitos: apontamento, achatamento, curvatura (nota $1=$ defeito mais acentuado a nota $5=$ ausência de defeito), aparência geral (nota $1=$ pior aparência a nota $5=$ melhor aparência), aspereza da pele (nota $1=$ pele áspera a nota 5 = pele lisa), uniformidade de tamanho e a uniformidade de formato (nota 1 = pouco uniforme a nota 5 = muito uniforme) e também a produtividade de tubérculos e o peso específico de tubérculos. A temperatura foi monitorada, sendo coletados os dados de temperatura média, mínima e máxima a cada três horas, em todos os experimentos. $\mathrm{Na}$ GS, os dados foram coletados na estação climatológica de Lavras, MG, e na PGC e SGC, na estação climatológica de Santa Rita do Sapucaí, MG.

As análises de variância individuais para cada experimento, a nível de famílias, foram realizadas empregando-se o software SAS. Pelo valor obtido no teste de F foi calculada a acurácia e com base nos quadrados médios foram estimados as herdabilidades, o coeficiente de variação genética (CVG) e o coeficiente de variação ambiental (CVE): pela razão entre os dois foi calculado o coeficiente de variaçáo relativo (b). Na PGC e na SGC foi realizada a soma de postos ou ranks (Mulamba e Mock, 1978) para os caracteres de aparência dos tubérculos.

\section{RESULTADOS E DISCUSSÃO}

A temperatura ideal para a cultura da batata, segundo relatos da literatura, está entre $14^{\circ} \mathrm{C}$ e $20^{\circ} \mathrm{C}$, pois nesse intervalo favorece a fotossíntese, reduz a respiraçáo da planta e favorece o acúmulo de reservas (Levy e Veilleux, 2007). As temperaturas observadas durante a condução dos experimentos foram favoráveis ao desenvolvimento da cultura na GS e na SGC (safra de inverno), tendo sido a porcentagem de horas com média abaixo de $20^{\circ} \mathrm{C}$ de 64,8 e de 64,5 horas, respectivamente. As temperaturas médias durante o ciclo da cultura foram de aproximadamente $18{ }^{\circ} \mathrm{C}$, com picos de $31{ }^{\circ} \mathrm{C}$ na GS e de $35^{\circ} \mathrm{C}$ na SGC. No experimento da PGC, realizado na safra das águas, verificou-se uma situação oposta à dos outros experimentos, nos quais apenas 33,7\% das horas tiveram temperatura abaixo de $20^{\circ} \mathrm{C}$. Na PGC, a temperatura média observada durante o experimento foi de $23{ }^{\circ} \mathrm{C}$, com máximas de $27^{\circ} \mathrm{C}$ e picos de $34^{\circ} \mathrm{C}$.

Com base nas médias das famílias na GS foi realizado o ordenamento delas no sentido da melhor para a pior, para todas as características avaliadas nessa geração (Tabela 1). Nessa fase, as médias das famílias apresentaram valores muito próximos, porém a superioridade das melhores famílias para os caracteres de aparência dos tubérculos pode ser explicada pela distribuiçáo da frequência de notas, na qual nas melhores famílias se observa maior porcentagem de indivíduos com notas superiores.

Com relação aos caracteres de aparência, algumas famílias se destacaram na GS por apresentarem maior frequência de tubérculos com ótima aparência geral. A família 4 (Tabela 1) apresentou mais de 60\% de clones com notas 4 e 5 (melhor aparência), também as famílias 13, 15, 16, 17 e 20 apresentaram mais de $40 \%$ de clones com as maiores notas. Com relação ao formato dos tubérculos, a maioria das famílias apresentou clones com tubérculos alongados (notas 4 e 5). As famílias 8, 16, 17, 19 e 24 (Tabela 1) apresentaram mais de $60 \%$ de clones alongados. A frequência média de clones com notas 1 e 2 (redondos) foi de $6,1 \%$ e a frequência máxima foi de apenas 16,2\%, para a família 15. De modo geral, para profundidade de olhos as famílias apresentaram tubérculos com olhos rasos ou superficiais (notas 4 e 5) e uma frequência baixa (média de 9,25\%) de olhos profundos ou moderadamente profundos (notas 1 e 2). Já para a característica aspereza da pele a situação foi completamente diferente, pois a frequência de clones com tubérculos de pele lisa (notas 4 e 5) foi de apenas 10,6\% (Tabela 1). Esse resultado mostra a dificuldade de se obter clones com pele lisa e brilhante, que é o padrão preferido pelo consumidor de cultivares de mesa.

A produtividade de tubérculos das famílias na GS variou de 20,6 a 43,5 gramas por planta, ou seja, a família 6, mais produtiva, produziu $111 \%$ a mais que a família 16 , menos produtiva (Tabela 1). Os valores baixos apresentados para a produtividade de tubérculos são devidos ao recipiente de cultivo utilizado na GS, o qual limita o crescimento do tubérculo. $\mathrm{O}$ peso específico de tubérculos nessa geração apresentou valores muito altos para algumas famílias, variando de 1,077 a 1,114. Essa é uma variação considerável entre as famílias para essa característica, pois tubérculos com peso específico em torno de 1,060 são adequados apenas para cozimento, porém acima de 1,077 já podem ser utilizados na indústria de pré-fritas congeladas ou para o preparo de massas. 
Tabela 1. Médias das famílias clonais na GS para produtividade (ProdT), peso específico (Pesp), formato (Form), textura da periderme (Pele), profundidade de olhos (Olho) e aparência geral dos tubérculos (Apg); Lavras, 2011

\begin{tabular}{|c|c|c|c|c|c|c|}
\hline Família & Prod. (g/planta) & P. Esp. & Form. & Pele & Olho & Ap. geral \\
\hline Família 1 & 31,23 & 1,0852 & 4,05 & 2,69 & 3,34 & 3,22 \\
\hline Família 2 & 38,71 & 1,0956 & 3,65 & 3,03 & 3,71 & 3,17 \\
\hline Família 3 & 36,20 & 1,0857 & 3,66 & 2,63 & 3,27 & 3,37 \\
\hline Família 4 & 33,88 & 1,0952 & 3,40 & 2,77 & 3,11 & 3,84 \\
\hline Família 5 & 40,83 & 1,0924 & 3,92 & 2,75 & 3,87 & 2,99 \\
\hline Família 6 & 43,51 & 1,0855 & 4,06 & 2,47 & 3,66 & 3,00 \\
\hline Família 7 & 38,79 & 1,0990 & 3,96 & 3,15 & 4,08 & 3,30 \\
\hline Família 8 & 34,37 & 1,0965 & 4,23 & 2,78 & 3,38 & 3,03 \\
\hline Família 9 & 31,62 & 1,0913 & 3,76 & 2,76 & 3,68 & 3,14 \\
\hline Família 10 & 31,33 & 1,1118 & 3,79 & 2,91 & 3,79 & 3,20 \\
\hline Família 11 & 33,58 & 1,1023 & 3,51 & 3,12 & 3,03 & 3,31 \\
\hline Família 12 & 29,42 & 1,0984 & 3,92 & 3,31 & 3,46 & 2,93 \\
\hline Família 13 & 33,86 & 1,0930 & 3,70 & 2,99 & 3,23 & 3,47 \\
\hline Família 14 & 33,15 & 1,1137 & 3,30 & 2,94 & 3,66 & 3,20 \\
\hline Família 15 & 34,85 & 1,0884 & 3,03 & 2,16 & 3,32 & 3,34 \\
\hline Família 16 & 20,60 & 1,1002 & 4,42 & 2,77 & 3,14 & 3,43 \\
\hline Família 17 & 24,03 & 1,0935 & 4,51 & 2,92 & 2,93 & 3,33 \\
\hline Família 19 & 29,57 & 1,0766 & 4,14 & 2,51 & 3,10 & 3,08 \\
\hline Família 20 & 27,27 & 1,0834 & 3,69 & 2,67 & 2,98 & 3,44 \\
\hline Família 22 & 41,21 & 1,0898 & 3,87 & 2,43 & 3,65 & 2,85 \\
\hline Família 23 & 31,35 & 1,0892 & 3,87 & 2,38 & 2,94 & 3,05 \\
\hline Família 24 & 32,21 & 1,0891 & 4,18 & 2,32 & 2,88 & 3,43 \\
\hline
\end{tabular}

A utilização da GS na seleção de famílias tem sido proposta por alguns autores (Benavente et al., 2011; Bisognin e Douches, 2002; Love et al., 1997; Silva et al., 2008), porém, segundo Silva e Pereira (2011), ela não tem sido muito utilizada por ter sua eficiência questionada. A eficiência de seleção de famílias para caracteres de aparência dos tubérculos na GS foi relatada na literatura para formato, profundidade de olhos (Love et al., 1997), textura da periderme, apontamento achatamento e curvatura dos tubérculos (Silva et al., 2008). Para os caracteres avaliados na GS, no presente trabalho, verificou-se que apenas seria possível realizar a seleçáo nessa para o formato dos tubérculos. A inviabilidade da seleção para os demais caracteres de aparência dos tubérculos se deve, provavelmente, às condições de condução do ensaio na GS em casa de vegetação, em recipiente de volume reduzido e utilizando substrato organo-mineral.

Benavente et al. (2011) relatam a possibilidade de realizar a seleção para peso específico dos tubérculos na GS, devido à boa repetibilidade com as geraçóes seguintes. Benavente e Pinto (2012) sugerem a utilização da GS em seleção sequencial com a PGC para peso especifico dos tubérculos aplicando-se uma intensidade de seleçáo de $60 \% \mathrm{em}$ ambas, ou de $60 \%$ e $40 \%$, na GS e na PGC, respectivamente. Ao contrário dos resultados relatados por esses autores, não verificamos eficiência de seleção na GS para produtividade e peso específico dos tubérculos.

Com relação aos experimentos da PGC e da SGC houve diferença significativa, entre as famílias, para maioria das características avaliadas, indicando que existe variabilidade entre as famílias. As exceções foram achatamento e curvatura, na PGC, e uniformidades de tamanho e formato, textura da periderme e aparência geral dos tubérculos, na SGC. Observa-se que, para a maioria das características avaliadas, os valores das acurácias foram superiores a 0,7 , o que indica uma boa precisão experimental (Tabela 2). Resende e Duarte (2007) comentam que acurácias entre 0,7 e 0,9 determinam uma classe de precisão alta, e acima de 0,9 , muito alta. Com relação às herdabilidades, observa-se que as da PGC foram superiores às da SGC, isto provavelmente ocorreu devido às diferenças no desenho experimental aplicado em cada geraçáo, no que se refere ao número de repetiçóes e à constituição da parcela. As razôes entre o coeficiente de variação genética $(\mathrm{CVg})$ e o coeficiente de variação ambiental $(\mathrm{CVe})$ foram menores que a unidade para a maioria dos caracteres, o que indica ser a maior parte da variação devida à variância ambiental (Tabela 2).

O comportamento das famílias para produtividade e peso específico de tubérculos na PGC e na SGC estão apresentadas nas figuras 1 e 2. Considerando o desempenho das famílias em cada geração, para produtividade de tubérculos, verifica-se que a maior parte das famílias foi superior à média na PGC, em condiçóes de calor (Figura 1), indicando possível tolerância a temperaturas elevadas. Quando comparadas com as testemunhas, apenas oito famílias apresentaram desempenho inferior ao do clone CBM22-19, que apresenta tolerância ao calor, segundo Lambert et al. (2006). Nenhuma família apresentou produtividade inferior à das testemunhas 
Tabela 2. Médias, herdabilidades $\left(\mathrm{h}^{2}\right)$, acurácia $(\mathrm{r})$, coeficiente de variação genética $(\mathrm{CVG})$ e relação entre o coeficiente de variação genética e o coeficiente de variação ambiental (b) da PGC e da SGC para produtividade (Prod), peso específico (Pesp), formato (Form), apontamento (Apont), achatamento (Achat), curvatura (Curv), uniformidade de formato (Uform), uniformidade de tamanho (Utam), textura de periderme (Pele), profundidade de olhos (Olho) e aparência geral dos tubérculos (Apg)

\begin{tabular}{|c|c|c|c|c|c|c|c|c|c|c|c|}
\hline \multicolumn{12}{|c|}{ PGC } \\
\hline \multirow{2}{*}{ FV } & \multicolumn{11}{|c|}{ Quadrado médio } \\
\hline & Prod & Pesp & Form & Apont & Achat & Curv & Uform & Utam & Pele & Olho & Apg \\
\hline Media & 738,88 & 1,0615 & 3,13 & 4,48 & 4,76 & 4,94 & 3,38 & 3,06 & 3,27 & 3,67 & 2,36 \\
\hline Média fam. & 762,80 & 1,0609 & 3,18 & 4,46 & 4,80 & 4,95 & 3,29 & 3,03 & 3,18 & 3,68 & 2,31 \\
\hline h & 0,60 & 0,45 & 0,81 & 0,51 & 0,46 & - & 0,57 & 0,62 & 0,81 & 0,51 & 0,49 \\
\hline$h(f)$ & 0,42 & 0,09 & 0,25 & 0,13 & 0,43 & - & 0,07 & 0,09 & 0,19 & 0,10 & 0,12 \\
\hline$r$ & 0,90 & 0,85 & 0,96 & 0,87 & 0,85 & - & 0,90 & 0,91 & 0,96 & 0,87 & 0,86 \\
\hline$r(f)$ & 0,82 & 0,81 & 0,93 & 0,87 & 0,63 & - & 0,78 & 0,81 & 0,91 & 0,85 & 0,85 \\
\hline CVG & 0,17 & 0,0030 & 0,20 & 0,07 & 0,05 & - & 0,12 & 0,14 & 0,17 & 0,08 & 0,12 \\
\hline CVG(f) & 0,11 & 0,0026 & 0,14 & 0,07 & 0,11 & - & 0,08 & 0,09 & 0,11 & 0,07 & 0,12 \\
\hline b & 1,23 & 0,91 & 2,06 & 1,03 & 0,92 & - & 1,15 & 1,27 & 2,09 & 1,01 & 0,99 \\
\hline$b(f)$ & 0,85 & 0,80 & 1,49 & 1,00 & 2,23 & - & 0,71 & 0,79 & 1,25 & 0,86 & 0,94 \\
\hline \multicolumn{12}{|c|}{ SGC } \\
\hline Media & 652,23 & 1,0754 & 3,13 & 4,38 & 4,43 & 4,62 & 3,63 & 3,12 & 3,51 & 4,36 & 2,12 \\
\hline Média fam. & 658,93 & 1,0755 & 3,14 & 4,36 & 4,46 & 4,61 & 3,63 & 3,11 & 3,51 & 4,39 & 2,10 \\
\hline h & 0,85 & 0,20 & 0,37 & 0,19 & 0,14 & 0,16 & 0,04 & - & 0,17 & 0,11 & 0,10 \\
\hline$h(f)$ & 0,85 & 0,18 & 0,34 & 0,17 & 0,10 & 0,12 & - & - & 0,06 & 0,06 & 0,04 \\
\hline$r$ & 0,95 & 0,91 & 0,96 & 0,91 & 0,87 & 0,89 & 0,67 & - & 0,89 & 0,85 & 0,83 \\
\hline$r f$ & 0,96 & 0,90 & 0,95 & 0,90 & 0,83 & 0,86 & 0,99 & - & 0,76 & 0,75 & 0,67 \\
\hline CVG & 26,62 & 62 10-5 & 0,08 & 0,02 & 0,02 & 0,01 & 0,01 & - & 0,05 & 0,02 & 0,02 \\
\hline CVGf & 27,35 & 54 10-5 & 0,07 & 0,02 & 0,02 & 0,01 & - & - & 0,02 & 0,01 & 0,01 \\
\hline b & 5,46 & 0,25 & 0,58 & 0,23 & 0,16 & 0,19 & 0,04 & - & 0,20 & 0,13 & 0,11 \\
\hline$b(f)$ & 5,61 & 0,22 & 0,51 & 0,21 & 0,12 & 0,14 & - & - & 0,07 & 0,06 & 0,04 \\
\hline
\end{tabular}

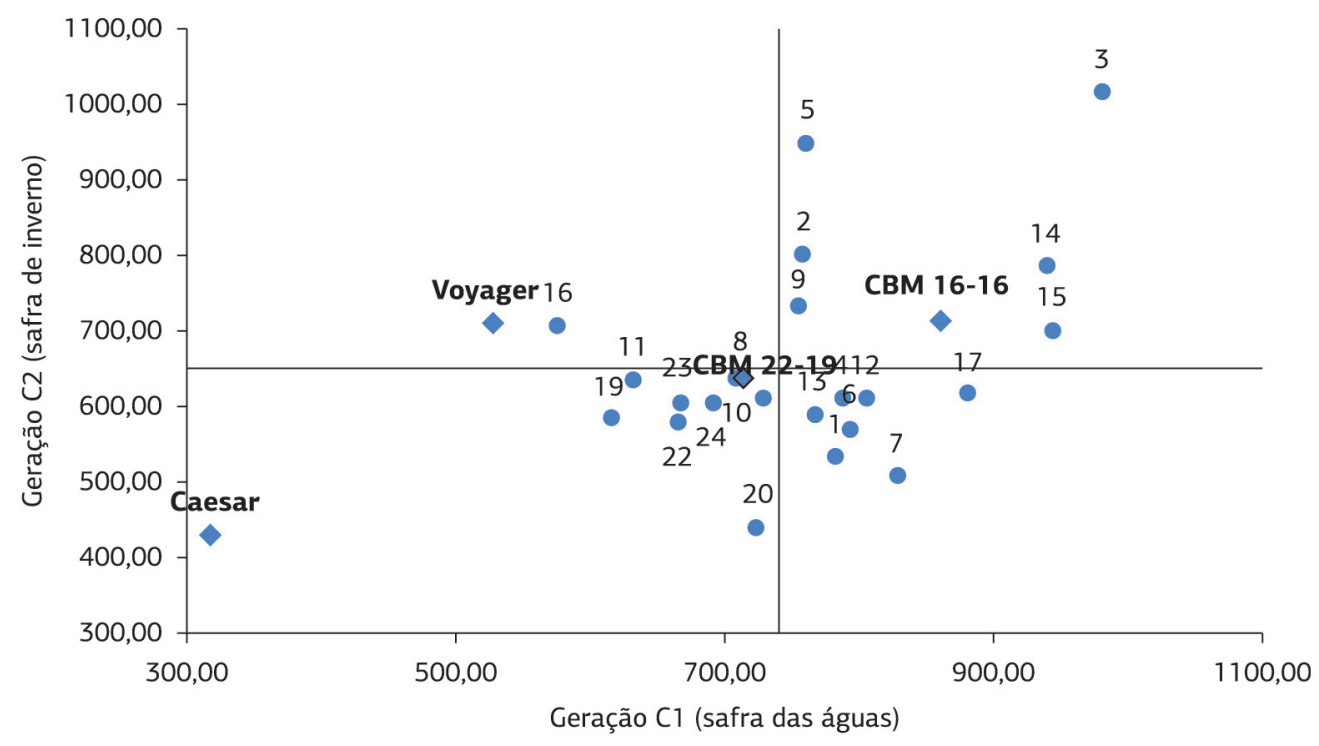

Figura 1. Produtividade de tubérculos na PGC e na SGC.

sob condiçóes de calor, indicando um progresso para essa característica.

Analisando o desempenho das famílias nas duas geraçóes pode-se observar que 36\% das famílias clonais (oito famílias) apresentaram desempenho abaixo da média de produtividade de tubérculos em ambas as gerações
(Figura 1). Aproximadamente $32 \%$ das famílias (sete famílias) apresentaram desempenho acima da média na PGC, sob temperaturas elevadas, porém em condiçóes de temperatura amena não responderam à melhoria das condições. Do total de famílias avaliadas, apenas $27 \%$ tiveram desempenho superior à média em ambas as geraçôes, ou seja, são tolerantes ao 


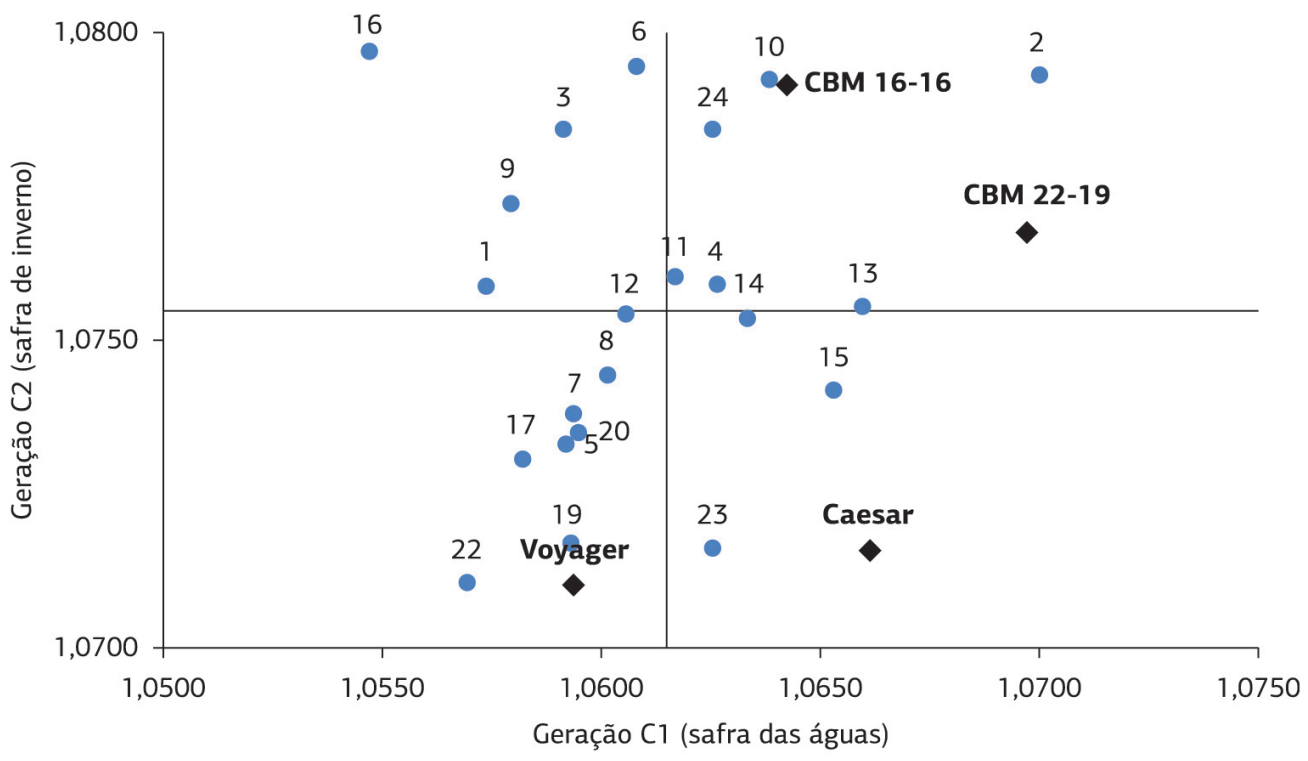

Figura 2. Peso específico dos tubérculos na PGC e na SGC.

calor e responsivas à melhoria das condiçóes de temperatura, assim como o clone CBM16-16 tolerante ao calor, segundo Lambert et al. (2006).

Para o peso específico de tubérculos verificou-se uma distribuiçáo mais uniforme das famílias clonais nos quadrantes (Figura 2), sendo que a porcentagem de famílias que foram superiores à média na PGC foi de $40 \%$, e na SGC, de $50 \%$. Das famílias que tiveram peso específico superior à média em condiçóes de calor, a maioria respondeu à melhoria na temperatura. Assim como os clones CBM16-16 e CBM22-19, as famílias que superaram a média nas duas condiçōes de cultivo podem ser classificadas como tolerantes ao calor e responsivas à melhoria da temperatura. No conjunto das três geraçóes observa-se que as famílias 2, 4, 10, 11 e 14 sempre tiveram um peso específico superior à média, indicando uma possibilidade de seleção ainda na GS. Destaque para a família 2, que apresentou comportamento superior para produtividade e peso específico de tubérculos nas três geraçóes avaliadas, indicando ser uma das famílias mais promissoras na obtenção de clones tolerantes ao calor e responsivos a melhoria do ambiente.

Sabe-se que dentro de cada família ocorre a segregação dos clones quanto ao desempenho em determinado ambiente, porém espera-se que a maioria dos clones tenha o mesmo comportamento da família de origem. Assim, baseando-nos no desempenho das famílias nas duas geraçôes, podemos selecionar para um ambiente específico, com relação a temperatura, ou adaptação ampla. A seleção de famílias tolerantes a altas temperaturas e responsivas às melhorias do ambiente, ou seja, de adaptaçáo ampla, parece ser a melhor estratégia, pois possibilita a obtenção de clones que suportam as oscilações do ambiente.

Benavente et al. (2011) comentam que a seleção de famílias para produtividade de tubérculos, na PGC, em condiçôes de calor, pode ser realizada com intensidades de seleção superiores a $30 \%$, por apresentarem alta repetibilidade nas geraçôes seguintes cultivadas tanto em condiçóes de calor como de temperatura amena. Segundo esses autores, para o peso específico dos tubérculos, a seleção pode ser realizada na mesma condição, porém com uma intensidade de seleçáo acima de 20\%. Casler e Brummer (2008), trabalhando com simulação de seleção entre e dentro de famílias de cana-de-açúcar, verificaram que a seleção de famílias deve ser praticada com intensidade de seleção mais branda e a seleção de clones, com uma intensidade igual ou maior.

$\mathrm{Na}$ tentativa de classificar as famílias quanto à aparência dos tubérculos foi estimada a soma de postos, índice de Mulamba e Mock (1978), para achatamento, apontamento, curvatura, textura da periderme, profundidade de olhos, uniformidade de tamanho, uniformidade de formato e aparência geral. $\mathrm{O}$ formato dos tubérculos, não foi incluído na soma, pois é uma característica classificatória da aptidáo de uso, não devendo ser agrupado com as demais características de aparência dos tubérculos, sendo tubérculos redondos indicados para a indústria de chips e os alongados e ovais, para uso doméstico e na indústria de palitos pré-fritos. Pelo ranqueamento das famílias, verifica-se que as famílias 3, 6, 9 e 19 apresentaram melhor aparência de tubérculos na PGC e SGC (Tabela 3). Não houve muita coincidência nas melhores famílias para soma dos caracteres de aparência entre a GS e a PGC e SGC. As diferenças ocorreram provavelmente devido na PGC e SGC, o cultivo ter sido realizado em campo e a um maior número de caracteres terem sido avaliados.

Verifica-se a eficiência da seleção de famílias através da classificação dos melhores clones da populaçáo. Se a seleçáo de famílias for eficiente, espera-se que a maioria dos melhores clones esteja dentro das melhores famílias. Observa-se que para produtividade, peso específico e para as características de 
Tabela 3. Média de formato e soma de postos das características de aparência das famílias na PGC e SGC

\begin{tabular}{|lcccc|}
\hline & \multicolumn{3}{c}{ PGC } & \multicolumn{2}{c|}{ SGC } \\
\hline Família & Formato & Aparência & Formato & Aparência \\
\hline Família 2 & 3,06 & 82 & 2,95 & 96 \\
\hline Família 3 & 3,75 & 80 & 2,90 & 81 \\
\hline Família 4 & 3,33 & 60 & 2,35 & 67 \\
\hline Família 5 & 2,33 & 82 & 2,40 & 86 \\
\hline Família 6 & 3,60 & 71 & 3,65 & 92 \\
\hline Família 7 & 2,64 & 49 & 3,65 & 78 \\
\hline Família 8 & 3,39 & 87 & 3,00 & 111 \\
\hline Família 9 & 3,27 & 81 & 3,44 & 82 \\
\hline Família 10 & 3,54 & 126 & 3,05 & 63 \\
\hline Família 11 & 2,87 & 130 & 2,25 & 85 \\
\hline Família 12 & 3,79 & 102 & 3,75 & 81 \\
\hline Família 13 & 2,78 & 96 & 2,95 & 90 \\
\hline Família 14 & 2,68 & 119 & 3,30 & 125 \\
\hline Família 15 & 2,47 & 80 & 2,45 & 96 \\
\hline Família 16 & 3,64 & 88 & 3,95 & 76 \\
\hline Família 17 & 4,07 & 89 & 4,00 & 77 \\
\hline Família 19 & 3,17 & 55 & 3,40 & 76 \\
\hline Família 20 & 3,05 & 94 & 2,80 & 79 \\
\hline Família 22 & 2,48 & 102 & 3,40 & 119 \\
\hline Família 23 & 3,31 & 108 & 3,25 & 94 \\
\hline Família 24 & 3,31 & 121 & 3,05 & 100 \\
\hline & & & & \\
\hline
\end{tabular}

aparência dos tubérculos, a seleção de famílias foi eficiente. A seleção de famílias para aptidôes de uso não foi eficiente devido ao fato de, pelas médias das famílias avaliadas, não ter sido possível observar a aptidão, havendo uma grande segregação dos clones dentro de cada família.

Para a produtividade de tubérculos e considerando as cinco melhores famílias (27\%), com base na média, da PGC e SGC, foi observado que $42 \%$ e $54 \%$ dos 50 melhores clones pertenciam as essas famílias. Quando se considera uma intensidade de seleção de famílias de 50\%, verifica-se que $64 \%$ e $76 \%$ dos mesmos 50 clones na PGC e SGC pertencem às famílias selecionadas. No caso de peso específico dos tubérculos observou-se a mesma tendência, ou seja, $48 \%$ e $42 \%$ dos 50 melhores clones na PGC e SGC, respectivamente, pertencem às cinco famílias com as melhores médias. Se a intensidade de seleção entre famílias for de $50 \%$, verifica-se que $72 \%$ e $86 \%$ dos clones superiores estavam nas 11 melhores famílias.

Para aparência dos tubérculos, a seleção de famílias foi menos eficiente. Considerando a seleção das cinco famílias (27\%) com maior média, na PGC e SGC apenas 34\% e $36 \%$ dos melhores 50 clones pertenciam a essas famílias. Quando se considera as 11 melhores famílias (50\%) de cada geração, a porcentagem de clones pertencentes a elas foi de $58 \%$ e $66 \%$ para PGC e SGC, respectivamente. A menor proporção de clones pertencentes às melhores famílias em

Tabela 4. Porcentagem dos 50 melhores clones por família, na PGC e SGC, para produtividade (Prod), peso específico (Pesp), aparência geral de tubérculos (Apg), mercado in natura (mesa) e indústria (Ind)

\begin{tabular}{|c|c|c|c|c|c|c|c|c|c|c|}
\hline \multirow{2}{*}{ Família } & \multicolumn{5}{|c|}{ PGC } & \multicolumn{5}{|c|}{ SGC } \\
\hline & Prod & Pesp & Apg & Mesa & Ind & Prod & Pesp & Apg & Mesa & Ind \\
\hline Família 1 & 4,0 & 4,0 & 8,0 & 8,0 & 4,0 & 0,0 & 6,0 & 0,0 & 2,0 & 0,0 \\
\hline Família 2 & 4,0 & 20,0 & 6,0 & 6,0 & 12,0 & 6,0 & 6,0 & 2,0 & 2,0 & 6,0 \\
\hline Família 3 & 4,0 & 4,0 & 4,0 & 8,0 & 4,0 & 14,0 & 10,0 & 4,0 & 14,0 & 6,0 \\
\hline Família 4 & 2,0 & 6,0 & 4,0 & 4,0 & 6,0 & 2,0 & 8,0 & 4,0 & 6,0 & 10,0 \\
\hline Família 5 & 2,0 & 0,0 & 4,0 & 4,0 & 8,0 & 20,0 & 4,0 & 4,0 & 14,0 & 0,0 \\
\hline Família 6 & 4,0 & 6,0 & 14,0 & 4,0 & 8,0 & 4,0 & 10,0 & 12,0 & 0,0 & 6,0 \\
\hline Família 7 & 10,0 & 4,0 & 2,0 & 6,0 & 2,0 & 2,0 & 4,0 & 2,0 & 4,0 & 0,0 \\
\hline Família 8 & 6,0 & 4,0 & 8,0 & 2,0 & 4,0 & 6,0 & 2,0 & 4,0 & 4,0 & 8,0 \\
\hline Família 9 & 0,0 & 0,0 & 2,0 & 0,0 & 0,0 & 8,0 & 8,0 & 12,0 & 4,0 & 6,0 \\
\hline Família 10 & 8,0 & 8,0 & 2,0 & 4,0 & 4,0 & 2,0 & 10,0 & 2,0 & 2,0 & 2,0 \\
\hline Família 11 & 4,0 & 4,0 & 2,0 & 2,0 & 2,0 & 2,0 & 8,0 & 4,0 & 2,0 & 2,0 \\
\hline Família 12 & 6,0 & 0,0 & 4,0 & 2,0 & 6,0 & 2,0 & 0,0 & 4,0 & 2,0 & 8,0 \\
\hline Família 13 & 4,0 & 8,0 & 6,0 & 4,0 & 4,0 & 6,0 & 2,0 & 6,0 & 4,0 & 2,0 \\
\hline Família 14 & 10,0 & 6,0 & 0,0 & 8,0 & 2,0 & 6,0 & 0,0 & 0,0 & 8,0 & 2,0 \\
\hline Família 15 & 8,0 & 6,0 & 6,0 & 8,0 & 6,0 & 2,0 & 2,0 & 4,0 & 6,0 & 6,0 \\
\hline Família 16 & 0,0 & 4,0 & 2,0 & 0,0 & 8,0 & 6,0 & 6,0 & 10,0 & 4,0 & 14,0 \\
\hline Família 17 & 10,0 & 0,0 & 6,0 & 8,0 & 6,0 & 4,0 & 0,0 & 12,0 & 2,0 & 6,0 \\
\hline Família 19 & 6,0 & 4,0 & 6,0 & 8,0 & 4,0 & 4,0 & 0,0 & 4,0 & 8,0 & 6,0 \\
\hline Família 20 & 4,0 & 2,0 & 10,0 & 6,0 & 2,0 & 0,0 & 2,0 & 2,0 & 0,0 & 0,0 \\
\hline Família 22 & 2,0 & 4,0 & 0,0 & 4,0 & 0,0 & 2,0 & 0,0 & 0,0 & 4,0 & 4,0 \\
\hline Família 23 & 0,0 & 0,0 & 2,0 & 2,0 & 2,0 & 0,0 & 0,0 & 6,0 & 8,0 & 0,0 \\
\hline Família 24 & 2,0 & 6,0 & 2,0 & 2,0 & 6,0 & 2,0 & 12,0 & 2,0 & 0,0 & 6,0 \\
\hline
\end{tabular}


relação a produtividade e peso específico dos tubérculos provavelmente ocorreu devido à complexidade desse caracter, já que a aparência dos tubérculos é composta por diversos componentes.

Pelos resultados apresentados neste trabalho verificou-se que, de uma maneira geral, tanto para caracteres de aparência como para produtividade e peso específico, a seleção de $50 \%$ das melhores famílias com base na média mostrou-se satisfatória, retendo a maior parte dos clones promissores. Para mostrar a eficiência da seleção de famílias, Simmonds (1996), utilizando-se de simulação, relatou que $60 \%$ dos melhores clones deveriam pertencer a $10 \%$ das melhores famílias, e $70 \%$ dos melhores clones seriam oriundos de $20 \%$ das melhores famílias. Benavente e Pinto (2012), que se propuseram a verificar a eficiência da seleção de famílias para tolerância ao calor, trabalharam com 30 famílias e simularam diferentes intensidades de seleção na GS e PGC, concluindo que o ideal é intensidade de $60 \%$ nas duas gerações.

A aptidão de uso dos clones pode ser definida pelo formato, peso específico e aparência dos tubérculos, devendo a produtividade ser a condição primária. Baseado nas médias dessas características podemos definir a aptidáo dos clones. Em ambas as geraçôes foram selecionados os 50 melhores clones para mercado in natura (mesa) e indústria e foi determinada a porcentagem de indivíduos pertencentes a cada família, indicando a aptidão.

O mercado para mesa, ou uso doméstico, prioriza tubérculos com boa aparência, de formato oval ou alongado e peso específico mediano, entre 1,070 e 1,077, que possibilita o multiuso, isto é, cozimento, preparo de massas, frituras etc. Para esse segmento de mercado pode-se observar que as famílias 3, 14 e 19 foram as que apresentaram, em ambas as geraçôes, maior número de clones com aptidão para mesa (Tabela 4). A indústria de processamento de palitos pré-fritos exige tubérculos alongados e peso específico acima de 1,078. Devido à oscilação do peso específico dos clones causada pela temperatura, entre as geraçôes, não foi possível ter uma clareza com relação a aptidão das famílias para o processamento industrial. Entretanto, as famílias 2, 10 e 13 apresentaram bom percentual de clones destinados para indústria em ambas as geraçôes (Tabela 4), sendo consideradas tolerantes ao calor e responsivas a melhoria das condições de temperatura.

\section{CONCLUSÃO}

A seleção de famílias se mostrou eficiente para produtividade e peso específico dos tubérculos, identificando famílias tolerantes ao calor e responsivas a temperaturas amenas.

A seleção de famílias para o conjunto de caracteres de aparência dos tubérculos se mostrou menos eficiente, sendo a seleção para cada característica individualmente mais eficiente.

Identificaram-se famílias com boa aptidão para os segmentos de indústria de palitos pré-fritos e uso doméstico dos tubérculos.

\section{AGRADECIMENTOS}

Ao $\mathrm{CNPq}$, pelo apoio financeiro e concessão de bolsa ao primeiro autor, e também à FAPEMIG, pelo apoio financeiro para execução do projeto.

\section{REFERÊNCIAS}

AMARO, G.B.; PINTO, C.A.B.P.; LAMBERT, E.S.; MARTINS NETO, L.L. Early selection of potato clones for tuber characters. Ciência e Agrotecnologia, v.27, p.585-589, 2003. http://dx.doi. org/10.1590/S1413-70542003000300013

BENAVENTE, C.A.T.; PINTO, C.A.B.P. Selection intensities of families and clones in potato breeding. Ciência e Agrotecnologia, v.36, p.60-68, 2012.

BENAVENTE, C.A.T.; PINTO, C.A.B.P.; FIGUEIREDO, I.C.R.; RIBEIRO, G.H.M.R. Repeatability of family means in early generations of potato under heat stress. Crop Breeding and Applied Biotechnology, v.11, p.330-337, 2011.

BISOGNIN, D.A.; DOUCHES, D.S. Early generation selection for potato tuber quality in progenies of late blight resistant parents. Euphytica, v.127, p.1-9, 2002. http://dx.doi.org/10.1023/A:1019983503697

BRADSHAW, J.E.; DALE, M.F.B.; SWAN, G.E.L.; TODD, D.; WILSON, R.N. Early-generation selection between and within pair crosses in a potato (Solanum tuberosum subsp. tuberosum) breeding programme. Theoretical and Applied Genetics, v.7, p.1331-1339, 1998. http://dx.doi.org/10.1007/s001220051026

CASLER, M.D.; BRUMMER, E.C. Theoretical expected genetic gains for Among-and-Within-Family selection methods in perennial forage crops. Crop Science, Madison, v. 48, p.890-902, 2008. http:// dx.doi.org/10.2135/cropsci2007.09.0499

DINIZ, M.C.; PINTO, C.A.; LAMBERT, E.S. Sample size for family evaluation in potato breeding programs. Ciência e Agrotecnologia, v.30, p.277-282, 2006. http://dx.doi.org/10.1590/S141370542006000200013

GOPAL, J. Between and within families variation and family selection in potato breeding programmes. Journal of Genetics and Breeding, v. 55 , p.313-318, 2001.

LAMBERT, E.S.; PINTO, C.A.B.P.; BENITES, F.R.G. Potato improvement for tropical conditions: I. Analysis of stability. Crop Breeding and Applied Biotechnology. v.6, p.129-135. 2006. http:// dx.doi.org/10.12702/1984-7033.v06n02a03 
LEVY, D.; VEILLEUX, R.E. Adaptation of potato to high temperatures and salinity: a review. American Journal of Potato Research, v.84, p.487-506, 2007. http://dx.doi.org/10.1007/BF02987885

LOVE, S.L.; WERNER, B.K.; PAVEK, J.J. Selection for individual traits in the early generations of a potato breeding program dedicated to producing cultivars with tuber having long shape and russet skin. American Potato Journal, v.74, p.199-213, 1997. http://dx.doi. org/10.1007/BF02851598

MELO, D.S.; PINTO, C.A.B.P.; PEIXOUTO, L.S.; NEDER, D.G.; ASSIS, J.C. Early selection of potato full-sib families. Ciência e Agrotecnologia, v.35, p.1101-1109, 2011. http://dx.doi.org/10.1590/ S1413-70542011000600009

MULAMBA, N.N.; MOCK, J.J. Improvement of yield potential of the method Eto Blanco maize (Zea mays L.) population by breeding for plant traits. Egyptian Journal of Genetics and Citology, v.7, p.40-51, 1978.
RESENDE, M.D.V.; DUARTE, J.B. Precisão e controle de qualidade em experimentos de avaliação de cultivares. Pesquisa Agropecuária Tropical, v.37, p.182-194, 2007.

SILVA, G.O.; PEREIRA, A.S.; SOUZA, V.; CARVALHO, F.I.F.; FRITSCHE NETO, R. Seleção para caracteres fenotípicos de tubérculos nas primeiras geraçôes em batata. Revista Ceres, v.55, p.168-172, 2008.

SILVA, G.O.; PEREIRA, A.S.; Seleçâo em geraçôes iniciais para caracteres agronômicos em batata. Horticultura Brasileira. v.29, p.499-455, 2011.

SIMMONDS, N.W. Family selection in plant breeding. Euphytica, v.90, p.201-208, 1996. http://dx.doi.org/10.1007/BF00023859

SIMON, G.A.; PINTO, C.A.B.P.; BENITES, F.R.G. Seleção de famílias clonais de batata em diferentes ambientes. Ciência e Agrotecnologia, v.33, p.164-169, 2009. http://dx.doi.org/10.1590/ S1413-70542009000100023 